\title{
Besonderheiten der Kindertuberkulose
}

\section{Characteristics of Childhood Tuberculosis}

\author{
Autoren \\ A. K. Detjen ${ }^{1,2}$, K. Magdorf ${ }^{1,3}$ \\ Institute \\ Klinik für Pädiatrie m.S. Pneumologie und Immunologie, Charité Universitätsmedizin, Berlin, Deutschland \\ Desmond Tutu TB Centre, Department of Paediatrics and Child Health, Faculty of Health Sciences, \\ Stellenbosch University, South Africa \\ Abteilung für pädiatrische Pneumologie und Allergologie, Helios Klinikum Emil von Behring, Berlin
}

Bibliografie

DOI $10.1055 / \mathrm{s}-0028-1100827$

Online-Publikation: 3. 3. 2009

Pneumologie 2009; 63: 207-218

(c) Georg Thieme Verlag KG

Stuttgart · New York

ISSN 0934-8387

\section{Korrespondenzadresse}

Dr. med. Klaus Magdorf

Abteilung für pädiatrische

Pneumologie und Allergologie, Helios Klinikum Emil von

Behring, Standort Campus Benjamin Franklin/Charité Hindenburgdamm 30 12200 Berlin

klaus.magdorf@charite.de anne.detjen@charite.de

Serienherausgeber

R. Loddenkemper, Berlin

T. Schaberg, Rotenburg

\section{Zusammenfassung}

Während die Inzidenz der Tuberkulose in den meisten westlichen Industrieländern rückläufig ist, gehört diese Infektionskrankheit weltweit zu den häufigsten Todesursachen im Kindesalter. Kinder werden meist durch Erwachsene in ihrem direkten Umfeld infiziert. Die klinische Manifestation ist direkte Folge der Primärinfektion und spiegelt damit die Übertragungsrate innerhalb der Gesellschaft wider. Kinder mit unbehandelter Infektion bleiben ein lebenslanger Pool für spätere Erkrankung und Infektionsquellen. Prävention und Therapie der latenten Tuberkulose-Infektion sind daher grundlegende Aufgaben des Gesundheitssystems. Kinder haben nach Infektion mit Mycobacterium tuberculosis ein besonders hohes Erkrankungsrisiko. Die Krankheit manifestiert sich unterschiedlich und häufig schwerwiegender als bei Erwachsenen. Gleichzeitig ist die Diagnose der Tuberkulose im Kindesalter aufgrund der oft unspezifischen klinischen Präsentation sowie der Schwierigkeit des kulturellen Erregernachweises eine besondere Herausforderung. Der Artikel gibt einen Überblick über die Besonderheiten der Epidemiologie, Klinik, Diagnostik und Behandlung der Tuberkulose im Kindesalter.

\section{Abstract \\ $\nabla$}

In spite of a decline in the western industrialised countries, tuberculosis remains one of the commonest causes of childhood mortality in the world. In most cases, children become infected by adults in their immediate environment. The clinical manifestation as a consequence of the primary infection reflects the community transmission of tuberculosis. Children with untreated infection remain a lifelong pool for future disease and therefore infectivity. Thus, prevention and therapy of latent tuberculosis infection are fundamental duties of the public health system. The risk of developing active disease following infection with Mycobacterium tuberculosis is especially high in children. Compared to adults, childhood tuberculosis manifests differently and is often more severe. At the same time, the diagnosis is complicated by the unspecific clinical presentation and difficulty of culture confirmation in children. This article gives an overview of the special features of the epidemiology, clinical presentation, diagnosis and management of childhood tuberculosis.

\section{Epidemiologie der Kindertuberkulose \\ $\nabla$}

Kinder machen nach Schätzungen der Weltgesundheitsorganisation (WHO) ca. 9-11\% der jährlich knapp über 9 Millionen weltweit auftretenden Tuberkulosefälle aus [1-3]. Da ca. 95\% der Kinder unter 12 Jahren färberisch negativ sind, dürfte die eigentliche Anzahl der Tuberkulosen im Kindesalter unterschätzt sein $[4,5]$. Die geografische Ausbreitung der Tuberkulose reflektiert, wie stark ihre Epidemiologie von sozioökonomischen Faktoren sowie von einem funktionierenden Gesundheitssystem beein- flusst wird: In Industrieländern machen Kinder ca. 2-7\%, in einkommensschwachen Ländern aber 15-40\% der Fälle aus [5]. In Deutschland, einem Tuberkulose-Niedriginzidenzland (Inzidenz $<10 / 100000)$, ist die Zahl der gemeldeten Tuberkulosefälle in den letzten Jahren kontinuierlich rückläufig. Im Jahr 2006 erkrankten nur noch 5402 Menschen an einer Tuberkulose (6,6/100000), 195 davon waren Kinder $(1,7 / 100000)$ [6,7]. Ca. zwei Drittel aller Fälle waren infektiös.

Die Migration aus Ländern mit mittlerer bis hoher (>50/100 000) Tuberkuloseinzidenz, v.a. aus 
Osteuropa, trägt dazu bei, dass die Tuberkulose auch in Deutschland weiterhin nicht zu vernachlässigen ist. Die Inzidenz lag 2006 bei Personen ausländischer Staatsbürgerschaft 5-mal höher als bei deutschen Staatsangehörigen, bei Kindern sogar 11-mal [7].

Ein weiteres Problem stellt die weltweite Zunahme medikamentenresistenter Tuberkulosestämme dar. In ihrem 2008 veröffentlichten Report schätzt die Weltgesundheitsorganisation (WHO), dass durchschnittlich ca. 4,8\% der 2006 neu aufgetretenen weltweiten Tuberkulosefälle durch multiresistente (MDR, multidrug resistant) Stämme verursacht werden. Der weltweit höchste Anteil an Resistenzen tritt in Osteuropa und den neuen unabhängigen Staaten (NUS) auf [8]. Weltweit Aufsehen erregte die Definition und nachfolgend gehäufte Diagnose von XDR-Tuberkulose (extensively drug resistant), Mycobacterium-tuberculosis-Stämme, die mindestens gegen die wichtigsten Medikamente erster Wahl (Isoniazid und Rifampizin im Sinne einer MDR-Tuberkulose), aber auch gegen eines der Fluorchinolone sowie eine der injizierbaren Substanzen aus der Gruppe der Zweitrangmedikamente (Amikacin, Kanamycin, Capreomycin) resistent und damit extrem schwer zu therapieren sind [9]. Nach bisher veröffentlichten Daten macht die XDR-Tuberkulose im Durchschnitt einen Anteil von ca. 7\% der MDR-Tuberkulosen aus [8].

In Deutschland kam es 2006 zu einem leichten Rückgang von Fällen mit MDR-Tuberkulose auf 2,2\% gegenüber 2,7\% in 2005; durchschnittlich 12,8\% wiesen eine Resistenz gegen eines der 5 Erstrangmedikamente (jegliche Resistenz) auf [7]. Im Ausland geborene Erkrankte wiesen einen signifikant höheren Anteil resistenter Erreger auf als in Deutschland geborene (17,7\% versus 9\% jegliche Resistenz) [7]. Bei Kindern mit Kontakt zu resistenter Tuberkulose ist davon auszugehen, dass sie mit demselben $M y$ cobacterium-tuberculosis-Stamm der Infektionsquelle infiziert sind, auch wenn der bakterielle Nachweis bei Kindern häufig nicht gelingt.

Die Kenntnisse über die epidemiologischen Hintergründe und Zusammenhänge sind für die Erkennung und Bekämpfung der Tuberkulose in Deutschland von großer Bedeutung.

Die wichtigste Infektionsquelle für Kinder sind Erwachsene, meist aus dem engen Umfeld (Eltern, Verwandte). Kinder, v.a. Kleinkinder, sind nur selten infektiös, da sie in den meisten Fällen nur geringe Bakterienzahlen aufweisen (paucibazilläre Tuberkulose) und darüber hinaus einen weniger ausgeprägten Hustenstoß haben. Es gibt jedoch vereinzelt Berichte von Tuberkuloseausbrüchen in Schulen, bei denen Kinder andere Kinder infiziert haben [10].

Die Infektion mit Mycobacterium tuberculosis erfolgt durch Übertragung von Aerosolpartikeln (Tröpfchenkerne) bei Kontakt mit Personen mit aktiver, offener Tuberkulose. In den meisten Fällen ist die Lunge betroffen, sehr selten kann eine Primärinfektion über die Tonsillen, den Gastrointestinaltrakt (meist Mycobacterium bovis) oder offene Wunden erfolgen [11]. Das Infektionsrisiko steigt, wenn die Kontaktperson mikroskopisch nachweisbar Mykobakterien im Sputum aufweist sowie mit der Dauer der Exposition in geschlossenen Räumen. Sonnen- oder Ultraviolettlicht sowie gute Raumdurchlüftung senken das Infektionsrisiko. Tuberkulose ist weniger infektiös als zum Beispiel Masern und Varizellen mit einem 90-100\% Infektions- und nachfolgendem Erkrankungsrisiko: nur ca. 50\% der Kinder mit engem Kontakt zu Tuberkulose werden infiziert [12]. Nach Infektion besteht ein lebenslanges Risiko an einer Tuberkulose zu erkranken, die Wahrscheinlichkeit ist jedoch mit $80 \%$ in den ersten 2 Jahren nach Infektion am höchsten [11]. Das Erkrankungs- risiko hängt zusätzlich von verschiedenen Faktoren wie der Menge an Mykobakterien, dem Alter, Immunstatus sowie genetischen Faktoren ab. Immunkompetente Erwachsene haben ein lebenslanges Erkrankungsrisiko von ca. 10\%, HIV-infizierte Erwachsene hingegen ein Risiko von 5-15\% pro Jahr, an einer Tuberkulose zu erkranken $[13,14]$. Säuglinge und Kleinkinder haben nach unbehandelter Infektion mit bis zu $40 \%$ das höchste Erkrankungsrisiko [15].

\section{Pathogenese \\ $\nabla$}

Kinder besitzen zum Zeitpunkt der primären Infektion keine protektive Immunität gegen Mykobakterien. Die weniger als 2-5 $\mu \mathrm{m}$ großen Tröpfchenkerne, die jeweils zwischen 1-3 Mykobakterien enthalten, gelangen in die Alveolen und werden dort von Alveolarmakrophagen aufgenommen. Größere Partikel werden von den Zilien der Atemwege und des Bronchialbaums aufgefangen und durch die mukoziliäre Clearance beseitigt [16]. Es folgt eine zunächst lokale Immunreaktion durch unspezifisch aktivierte Alveolarmakrophagen, die geringe Mengen von Mycobacterium tuberculosis zerstören können. Treffen die Mykobakterien auf nicht aktivierte, zusätzlich chemotaktisch aus dem Blut hinzugekommene Makrophagen, so können sie sich aufgrund ihrer subtilen Resistenzmechanismen in diesen vermehren. Durch Präsentation von mykobakteriellen Antigenen kommt es zur Aktivierung von CD4- und CD8-T-Zell-Subpopulationen, die in ihrer Interaktion mit den Makrophagen imstande sind, die Vermehrung der Mykobakterien zu unterbinden [17]. Zytokine wie IL-12, Interferon-gamma (IFN- $\gamma$ ) und Tumor Necrosis Faktor-alpha (TNF- $\alpha$ ) spielen eine zentrale Rolle bei der Aktivierung von Makrophagen und der Ausbildung einer ersten granulomatösen Läsion, die der Eindämmung und Wachstumshemmung der Mykobakterien dient und klinisch und radiologisch noch nicht sichtbar ist. Parallel dazu kommt es 2-10 Wochen nach Infektion zur Entwicklung einer Hypersensitivitätsreaktion vom Typ IV (delayed-type), die zur Gewebszerstörung und zentralen Nekrose der Läsion beitragen kann. Die Reaktion im Tuberkulin-Hauttest (THT) wird positiv [11].

Ob es aber überhaupt nach Infektion zur Ausbildung einer klinisch manifesten Tuberkulose kommt, hängt von der Balance zwischen der Virulenz und Menge der Mykobakterien und der Kompetenz des Immunsystems ab. T-Zelldefekte sowie genetisch bedingte Defekte der IL-12- und IFN- $\gamma$-Rezeptor-Achse führen zu einer erhöhten Suszeptibilität für Tuberkulose [18]. In den meisten Fällen heilt die Infektion nach dem Stadium der Granulombildung aus. Vereinzelte Mykobakterien können jedoch innerhalb kleinster Granulome persistieren (latente TuberkuloseInfektion, LTBI) und zu einem späteren Zeitpunkt reaktiviert werden [19]. Dies führt dann zur Ausbildung einer postprimären Tuberkulose.

Im Rahmen der Primärinfektion können Mykobakterien über die Lymphgefäße in die regionalen Hiluslymphknoten und über den Ductus thoracicus in die Blutbahn gelangen. Es kann zur asymptomatischen Ablagerung von Bakterien und Ausbildung kleinster Granulome in verschiedenen Organen wie den Meningen, Knochen und Nieren kommen. Vor allem bei Kleinkindern kann es aber auch im Rahmen dieser Streuung zur Ausbildung einer disseminierten Tuberkulose kommen.

Die Entwicklung der spezifischen zellvermittelten Immunreaktion kann zur Größenzunahme des primären Granuloms (Ghon'scher Herd) und der drainierenden Hiluslymphknoten 
führen. Beides wird zu diesem Zeitpunkt radiologisch als so genannter Primärkomplex sichtbar. Die Primärtuberkulose beschreibt das Fortschreiten der Erkrankung und Erregerausbreitung nach Bildung des Primärkomplexes [20]. Die häufigste Manifestation im Kindesalter ist die pulmonale Tuberkulose.

Nach Reaktivierung einer LTBI kommt es zur Ausbildung einer so genannten Postprimär- oder „adult-type“-Tuberkulose. Eine Reinfektion (v.a. in Gegenden mit einer hohen Tuberkuloseprävalenz) ist ebenfalls möglich. Konditionen, bei denen das Immunsystem geschwächt ist, wie im Alter und bei bestimmten Erkrankungen wie Malignomen, fortgeschrittene Niereninsuffizienz, aber auch die Gabe von immunsuppressiven Medikamenten (zytostatische Chemotherapie, TNF- $\alpha$-Blocker, Kortikosteroide) erhöhen das Risiko einer Reaktivierung [16].

\section{Klinische und radiologische Manifestation \\ $\nabla$}

Exponierte Kinder werden in Deutschland in ca. 50\% der Fälle durch Umgebungsuntersuchungen identifiziert [7]. Dadurch wird ein großer Teil der Kinder bereits im Stadium der Infektion oder frühen Erkrankung diagnostiziert und zeigt häufig noch keine oder nur sehr unspezifische Symptome. Komplizierte Formen der Tuberkulose werden gerade auch im Kindesalter häufig verkannt und zu spät diagnostiziert. Aus diesem Grund ist es wichtig, die Risikofaktoren und Anzeichen einer Tuberkulose zu kennen und sie bei differenzialdiagnostischen Überlegungen zu berücksichtigen.

\section{Latente Tuberkuloseinfektion}

$\nabla$

Die LTBI als Infektion ohne klinisch oder radiologisch sichtbaren Organbefall verläuft meist inapparent. Gelegentlich kann es zu grippeartigen Symptomen mit leichtem Fieber kommen.

\section{Tuberkulose}

$\nabla$

Auch eine unkomplizierte Tuberkulose ist im Frühstadium häufig asymptomatisch. Mit der Zeit entstehen unspezifische Allgemeinsymptome wie Fieber, Nachtschweiß, Gewichtsverlust, Müdigkeit. Je nach Manifestation zeigen sich organspezifische Symptome.

\section{Intrathorakale Tuberkulose}

Der Befall intrathorakaler Lymphknoten und/oder des Lungenparenchyms ist die häufigste Manifestationsform der Tuberkulose im Kindesalter. Die unkomplizierte Lymphknotentuberkulose verläuft häufig klinisch inapparent. Mit der Zeit können sich die o.g. Allgemeinsymptome entwickeln. Symptome wie Stridor oder Giemen können als Folge einer Kompression der Atemwege durch vergrößerte Lymphknoten entstehen. Bei zunehmender Inflammation kann es zu einer chronischen Hustensymptomatik kommen. Im Gegensatz zur akuten bakteriellen Pneumonie zeigen selbst Kinder mit fortgeschrittenem pulmonalem Befall häufig wenig akute Krankheitszeichen.

Eine anterior-posteriore sowie laterale Thorax-Röntgenaufnahme gehört zur Standarddiagnostik der pulmonalen Tuberkulose. Besonders im Kindesalter hilft die laterale Aufnahme, vergrößerte mediastinale und hiläre Lymphknoten zu erkennen. Kompressionen der Trachea oder Hauptbronchien sind besonders gut in Hartstrahlaufnahmen zu erkennen und sind oft ein indirektes Zeichen für Lymphknotenschwellung. Der Ghon'sche Herd ist meist nur innerhalb der ersten 6-8 Wochen nach Infektion radiologisch sichtbar, während Lymphknotenschwellungen als Zeichen der Primärtuberkulose bestehen bleiben. Folgen von Atemwegsverengungen, Lymphknoteneinbrüchen oder Disseminierung zeigen sich bei einer komplizierten Tuberkulose als Pneumonie, Segment- oder Lappenatelektasen oder mit einem miliaren Bild [21]. Typische radiologische Veränderungen bei pulmonaler Tuberkulose im Kindesalter sind in $\bullet$ Abb. 1 dargestellt (eine umfassendere Übersicht kann kostenlos von der

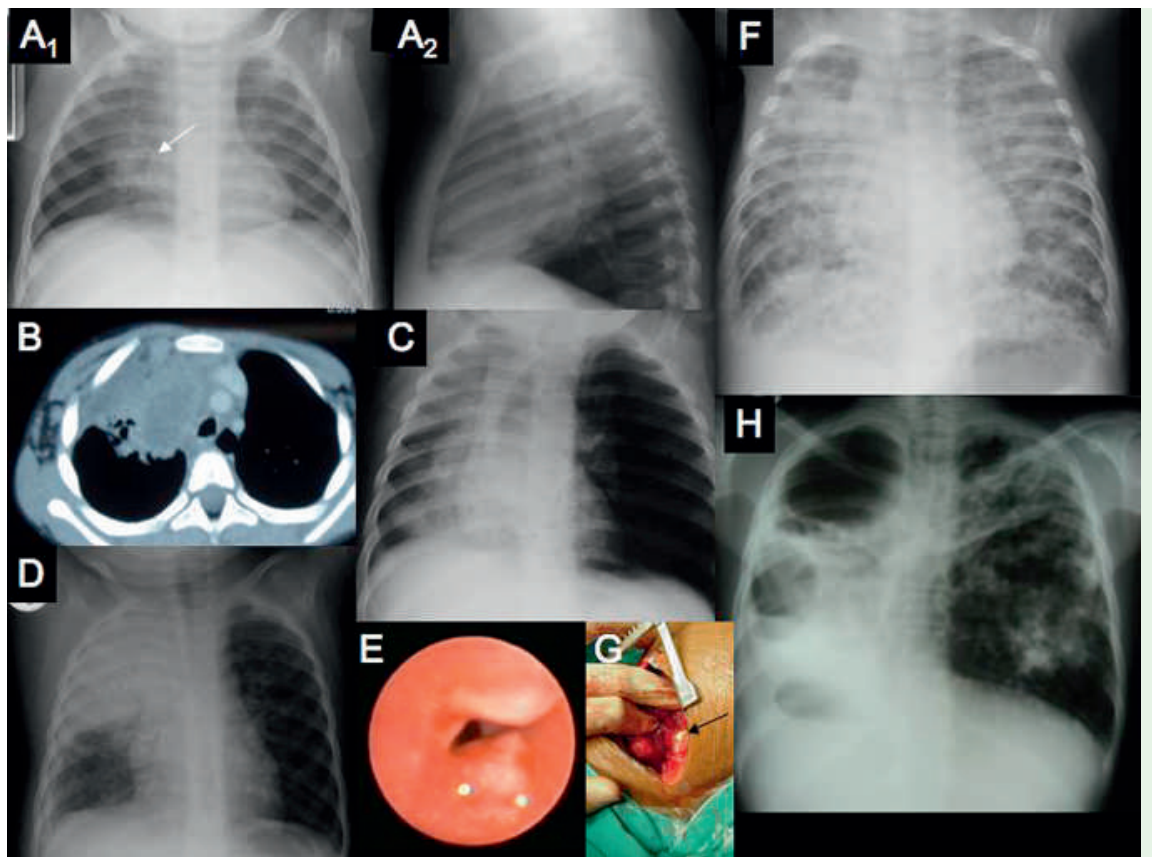

Abb. 1 Pulmonale Manifestationen der Tuberkulose. Primärtuberkulose mit Hiluslymphknotenvergrößerung und Kompression des rechten Hauptbronchus $(A)$ in der anterior-posterioren $\left(A_{1}\right)$ und lateralen $\left(A_{2}\right)$ Thorax-Röntgenaufnahme. Die Lymphknoten zeigen in der CT eine ringförmige Kontrastmittelanreicherung (B). Durch Kompression der Hauptbronchien kann ein Ventileffekt entstehen, der zur Überblähung einer Lunge führt (C). Durch Einbruch eines Lymphknotens in den Bronchus ( $E$, bronchoskopische Darstellung) und Streuung von infektiösem Material in die Peripherie kommt es zur Entwicklung einer spezifischen Pneumonie, die entweder einen Lungenlappen (D) oder die ganze Lunge betreffen kann (F). Stark vergrößerte Lymphknoten müssen in seltenen Fällen bronchoskopisch oder chirurgisch ausgeräumt bzw. entfernt werden $(\mathrm{G})$. Reaktivierung einer latenten Tuberkuloseinfektion (LTBI) führt zur Postprimärtuberkulose mit Ausbildung von Kavernen (H). 


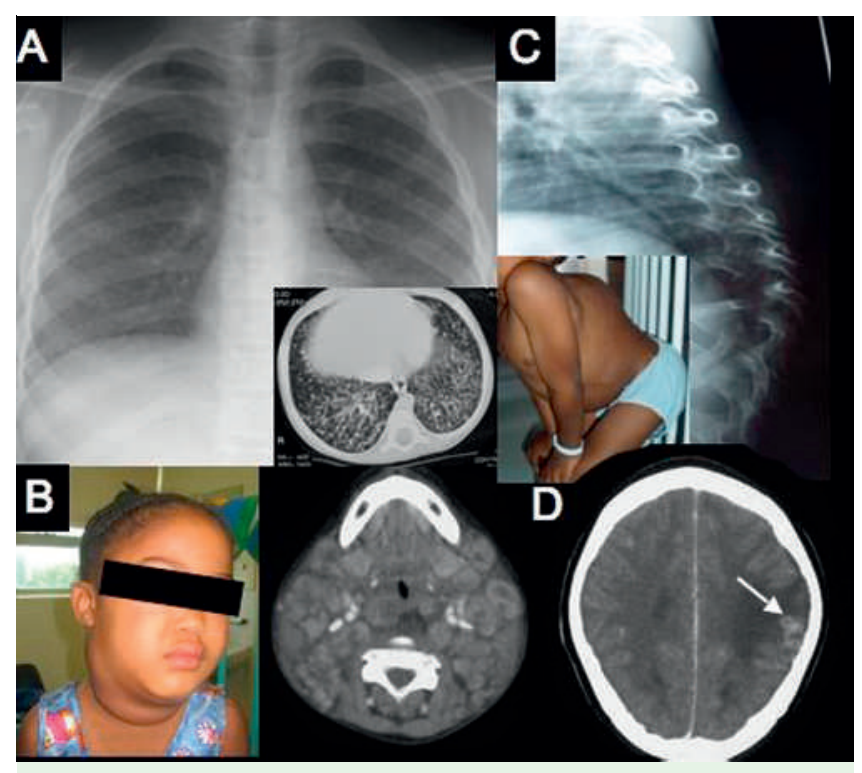

Abb.2 Dissemination und extrapulmonale Manifestationen der Tuberkulose. Eine hämatogene Streuung von Mykobakterien kann zur Ausbildung einer Miliartuberkulose führen. Im Röntgenbild und in der CT sind über die gesamte Lunge gleichmäßig verteilte kleinste Granulome („millet-seeds“) sichtbar (A). Die häufigste Form der extrapulmonalen Tuberkulose ist der Befall zervikaler Lymphknoten, meist ein-, in dieser Darstellung bei einem 4-jährigen Mädchen beidseitig (B). Die Spondylitis tuberculosa kann zum Zusammenbruch von Wirbelkörpern und Ausbildung eines Gibbus führen (C). Tuberkulome und meningeale Kontrastmittelanreicherung sind typische Zeichen einer Meningitis tuberculosa (D).

Homepage der International Union against Tuberculosis and Lung Disease heruntergeladen werden: Diagnostic Atlas of Intrathoracic Tuberculosis in Children. www.iuatld.org). Die radiologischen Veränderungen sind jedoch oft untypisch, v.a. bei Kleinkindern oder HIV-infizierten Kindern. Eine Lungentuberkulose kann daher mit einer Thorax-Röntgenaufnahme alleine nicht sicher ausgeschlossen werden.

Bei Verdacht auf komplizierte Formen oder Miliartuberkulose kommt die Computertomografie (CT) zum Einsatz. Ein radiologisches Zeichen für tuberkulöse Lymphknoten ist eine ringförmige Kontrastmittelanreicherung (enhancement) um vergrößerte Lymphknoten ( $\bullet$ Abb. 1).

Kavernen, meist in den apikalen Segmenten der Unterlappen oder Pleuraergüsse, sind ein typisches Zeichen der Postprimärtuberkulose.

\section{Pleuritis und Pericarditis tuberculosa}

Pleuraergüsse kommen bei bis zu 38\%, Perikardergüsse bei $1-2 \%$ der Kinder mit intrathorakaler Tuberkulose vor [22]. Bei Verdacht sollte eine Ultraschalluntersuchung durchgeführt werden.

\section{Extrathorakale Tuberkulose}

In Deutschland wurden 2006 22,6\% der Kinder mit einer extrapulmonalen Tuberkulose diagnostiziert [7]. Eine gleichzeitig bestehende pulmonale Beteiligung sollte immer radiologisch ausgeschlossen werden. Häufige Manifestationsformen der extrathorakalen Tuberkulose sind in $\bullet$ Abb. 2 dargestellt.

Am häufigsten kommt es zum unilateralen Befall der zervikalen Lymphknoten mit einer initial schmerzlosen, prallen Schwellung. Im Verlauf können die Lymphknoten konfluieren und, wenn un- behandelt, die Haut ulzerieren und perforieren. Allgemeinsymptome sind selten. Beim Auftreten einer persistierenden zervikalen Lymphadenopathie, die nicht auf Breitspektrumantibiotika anspricht, sollte eine Lymphknotentuberkulose sowie eine pulmonale Tuberkulose ausgeschlossen werden. Differenzialdiagnostisch kommen vor allem im Kleinkindalter so genannte nicht-tuberkulöse Mykobakterien (NTM) als Erreger infrage, am häufigsten Mycobacterium avium. Die Inzidenz der durch NTM verursachten Mykobakteriosen bei Kindern scheint in Deutschland und anderen westeuropäischen Ländern in den letzten Jahren anzusteigen [23-26]. Die Differenzierung der einzelnen Erregergruppen ist von Bedeutung, da sich ihre Therapie unterscheidet. Während die Tuberkulose obligat medikamentös behandelt wird, werden mit NTM befallene Lymphknoten nur chirurgisch exzidiert [27]. Eine additive medikamentöse Therapie ist selten indiziert [28].

Die Knochen- oder Gelenkstuberkulose entsteht aus noch nicht geklärten Gründen meist erst 3 - 5 Jahre nach der Primärinfektion [29]. Prädilektionsstelle ist die Wirbelsäule, v.a. die untere Brust- und Lendenwirbelsäule [11]. Lang andauernde Rückenschmerzen und Gewichtsverlust sind oft das erste Zeichen einer Spondylitis tuberculosa, im fortgeschrittenen Stadium kommt es zum Auftreten einer fortschreitenden Kyphose und Ausbildung eines so genannten Gibbus, verursacht durch den Einbruch von Wirbelkörpern. Eine Einengung des Spinalkanals kann zu neurologischen Ausfällen führen. Ein paraspinaler oder Psoasabszess, der Schmerzen bei der Hüftbeugung verursacht, ist eine häufige Komplikation.

\section{Meningitis tuberculosa}

Die tuberkulöse Meningitis, eine der schwerwiegendsten Formen der Tuberkulose, kann, meist 3-12 Monate nach der Primärinfektion, durch den Einbruch von tuberkulösen Herden in den Subarachnoidalraum entstehen [11,29]. Am häufigsten sind Kleinkinder betroffen. In Deutschland wurden 20064 Kinder mit einer Meningitis tuberculosa diagnostiziert [7]. Es kommt zu einer massiven granulomatösen Inflammation, Hyperkoagulopathie und lokalen Vaskulitis [30]. Im Liquor finden sich oft vermehrt Lymphozyten, erhöhtes Eiweiß und erniedrigte Glukosewerte ( $<50 \%$ des Blutglukosewertes), eine Serum-Hyponatriämie ist ebenfalls häufig.

Initialsymptome der Meningitis tuberculosa wie Abgeschlagenheit, Appetitmangel und leichte Stimmungsschwankungen, aber auch Kopfschmerzen, Übelkeit und Erbrechen entwickeln sich meist schleichend. Sie sind unspezifisch und führen häufig zu Fehldiagnosen wie Gastroenteritis oder unspezifische Atemwegsinfektionen. Im Verlauf kommt es zu fokalen Symptomen wie Hirnnervenausfällen. Vaskulitis und Hyperkoagulabilität mit erniedrigtem Protein S und erhöhtem Faktor VIII erhöhen das Risiko für Hirninfarkte [30]. Eine Obstruktion des Liquorflusses bzw. vermehrte Produktion bewirken die Ausbildung eines Hydrozephalus mit Entwicklung von Hirndruckzeichen. Im Spätstadium kommt es zum Koma ( Tab.1). In der CT stellt sich die meningeale Entzündung als basale Kontrastmittelanreicherung dar, Hydrozephalus und Infarkte können ebenfalls vorhanden sein. Zusätzlich finden sich im Verlauf häufig Tuberkulome im Gehirn, die je nach Lokalisation fokale Symptome, aber auch Hirndruckzeichen auslösen können [33] ( $\bullet$ Abb.2). Statt des CT eignet sich auch die Magnetresonanztomografie (MRT) für die Diagnose der Meningitis tuberculosa. In ca. 30-50\% der Fälle bestehen gleichzeitig tuberkulöse Veränderungen in der Röntgenaufnahme des Thorax [32]. 


\begin{tabular}{|c|c|c|}
\hline Stadium & Symptome & Prognose \\
\hline Stadium I & $\begin{array}{l}\text { Glasgow Coma Scale (GCS) 15, leichte menin- } \\
\text { geale Reizung, unspezifische Symptome wie } \\
\text { Abgeschlagenheit, Appetitlosigkeit }\end{array}$ & komplette Remission in den meisten Fällen \\
\hline Stadium II & $\begin{array}{l}\text { GCS } 11 \text { - 14, Verwirrung, fokale Zeichen wie } \\
\text { Hirnnervenausfälle }\end{array}$ & $\begin{array}{l}\text { inkomplette Remission mit mentalen oder } \\
\text { physischen Symptomen }\end{array}$ \\
\hline Stadium III & $\begin{array}{l}\text { GCS 10, Stupor/Koma, mit oder ohne fokale } \\
\text { Ausfälle, komplette Hemiplegie, seltener } \\
\text { Tetraplegie }\end{array}$ & $\begin{array}{l}\text { in } 30 \% \text { letal, schwere mentale oder physische } \\
\text { Schädigung }\end{array}$ \\
\hline
\end{tabular}

Tab. 1 Klinische Stadien und Prognose der Meningitis tuberculosa (nach [11,31,32]).
Die Mortalität der Meningitis tuberculosa ist bei fortgeschrittenen Verläufen hoch, die frühe Diagnose und Behandlung sind daher prognostisch von großer Bedeutung [32]. Langzeitfolgen wie Wahrnehmungsstörungen, Lernschwierigkeiten, emotionale Instabilität, aber auch motorische Defizite sind vor allem bei fortgeschrittenen Verläufen häufig [32,34].

\section{Miliartuberkulose}

Die Miliartuberkulose macht im Kindesalter ca. 0,5\% der Tuberkulosen aus [35]. Sie kommt überwiegend im Säuglings- und Kleinkindalter vor und die Mortalität ist trotz Behandlung aufgrund der häufig späten Diagnosestellung relativ hoch (15-20\%) [35]. Durch Einbruch eines verkäsenden Herdes in die Blutbahn und konsekutive massive hämatogene Streuung gelangen Mykobakterien als Mikroemboli in verschiedene Organe und es kommt zur Ausbildung von multiplen $<2 \mathrm{~mm}$ großen hirsekornähnlichen (milium=das Hirsekorn) Granulomen. Am häufigsten ist dies in der Lunge erkennbar. Per definitionem gehört zur Diagnose der Miliartuberkulose entweder die Präsenz von miliaren Infiltraten im Thorax-Röntgenbild oder der Nachweis von miliaren Tuberkeln in mehreren Organen mittels Sonografie oder ggf. MRT [35]. Die klinischen Symptome sind initial eher unspezifisch mit Fieber, Gewichtsverlust und Müdigkeit, können aber im weiteren Verlauf lebensbedrohliche Formen annehmen.

In ca. 20 - 40\% der Fälle besteht parallel eine tuberkulöse Meningitis, die in jedem Falle mittels Bildgebung und Lumbalpunktion ausgeschlossen werden muss [35]. Falls vorhanden, sind Tuberkel am Augenhintergrund (kalkspritzerartig) pathognomonisch für eine Miliartuberkulose [35].

Weitere, im Kindesalter sehr seltene Formen der extrathorakalen Tuberkulose betreffen den Urogenitaltrakt und die Haut.

\section{Konnatale Tuberkulose}

Eine extrem seltene, aber potenziell lebensbedrohliche Form ist die konnatale Tuberkulose. Die Tuberkulose bei einer Schwangeren wird aufgrund der relativ unspezifischen Symptome sowie der oft zurückhaltenden Durchführung von Thorax-Röntgenuntersuchungen häufig verkannt [36]. Die Infektion einer Schwangeren, die an einer tuberkulösen Plazentitis oder Endometritis leidet, wird hämatogen über die Umbilikalvenen auf das Kind übertragen. Der primäre Fokus findet sich meist in der Leber. Das Neugeborene kann Symptome wie Fieber, Lymphadenopathie, Hepatomegalie, aufgetriebenes Abdomen zeigen $[37,38]$. Die Infektion kann jedoch auch peripartal durch Aspiration von Amnionflüssigkeit oder direkten Kontakt mit infiziertem Gewebe stattfinden und zur Primärinfektion der Lunge mit nachfolgenden pneumonieähnlichen Symptomen und respiratorischer Insuffizienz führen. Das Risiko der Dissemination ist hoch. Auch beim Neugeborenen sind die Symptome, die selten direkt nach Geburt, sondern meist erst nach 2 - 3 Wochen beginnen, unspezifisch und werden häufig mit bakterieller Sepsis oder anderen neonatalen Infektionen verwechselt [36-38]. Der THT ist zum Zeitpunkt der Diagnose fast immer negativ, bei Verdacht sollte die Plazenta der Mutter post partum histologisch auf Granulome untersucht werden [37].

\section{Diagnostik der LTBI und der Tuberkulose im Kindesalter $\nabla$}

\section{Diagnose der LTB}

Die Diagnose der LTBI basiert auf einer Expositionsanamnese, der Einschätzung des Infektionsrisikos, einem positiven THT, neuerdings bestätigt durch einen IFN- $\gamma$ Release Assay (IGRA, siehe unten), sowie dem Ausschluss von klinischen Symptomen und Veränderungen im Thorax-Röntgenbild, die für eine aktive Tuberkulose sprechen.

Ein einfacher Fragebogen hilft, das Risiko für eine tuberkulöse Infektion mit einer hohen Wahrscheinlichkeit auszuschließen $[39,40]$ :

- Hat Ihr Kind Kontakt zu einer Person mit Tuberkulose gehabt?

- Ist Ihr Kind oder jemand aus Ihrer Familie in einem Land mit einer hohen Tuberkulosehäufigkeit geboren oder hat sich innerhalb der letzten 2 Jahre für längere Zeit in einem solchen Land aufgehalten (z. B. Osteuropa, Russland, Afrika, Ostasien)?

- Hat Ihr Kind regelmäßig Kontakt mit Jugendlichen/Erwachsenen, die ein hohes Tuberkulose-Risiko besitzen (z. B. Obdachlose, Drogen-/Alkoholabhängige, HIV-Infizierte Personen)?

- Hat Ihr Kind eine HIV-Infektion oder einen Immundefekt?

Es wird empfohlen, dass Kinderärzte diesen Fragebogen jährlich abfragen. Falls eine der Fragen mit „ja“ beantwortet wird, sollte gezielt ein THT durchgeführt und ggf. eine weitere Diagnostik und Therapie eingeleitet werden [40,41]. Zusätzlich sollte bei Kindern mit verdächtigen klinischen Symptomen wie persistierendem Nachtschweiß, Husten, Gewichtsverlust oder Abgeschlagenheit, eine Tuberkulose in die differenzialdiagnostischen Überlegungen eingeschlossen werden.

Der THT wird nach der Mendel-Mantoux-Methode mit 0,1 ml Tuberkulin PPD RT23 (Staatens Serum Institute Kopenhagen, Dänemark) durchgeführt [42]. Das Ergebnis wird nach 48-72 Stunden als transversaler Indurationsdurchmesser in $\mathrm{mm}$ ermittelt und sollte im Impfausweis dokumentiert werden. Eine Hautrötung alleine hat keinen diagnostischen Stellenwert und wird bei der Ausmessung nicht berücksichtigt. Für die Interpretation eines positiven THT wurden verschiedene Indurations-cut-offWerte festgelegt, die das Alter des Kindes sowie epidemiologische und andere Risikofaktoren einbeziehen ( Tab.2) $[43,44]$. Der THT kann aufgrund von Kreuzreaktivität mit NTM sowie 


\begin{tabular}{ll}
\hline $\begin{array}{l}\text { Induration } \\
>5 \mathrm{~mm}\end{array}$ & $\begin{array}{l}\text { Risikopopulation } \\
\text { Kinder mit kürzlichem Kontakt zu infektiöser Tuberkulose } \\
\text { HIV-infizierte Kinder }\end{array}$ \\
\hline$>10 \mathrm{~mm}$ & $\begin{array}{l}\text { Kinder<4 Jahre ohne Kontakt zu Tuberkulose oder Risikogruppen } \\
\text { Kinder mit regelmäßigem Kontakt zu Risikopopulationen } \\
\text { Kinder mit dokumentierter THT-Konversion innerhalb der letzten 2 Jahre }\end{array}$ \\
\hline$>15 \mathrm{~mm}$ (Starkreaktion) & $\begin{array}{l}\text { Kinder }>4 \text { Jahre ohne Kontakt zu Tuberkulose oder Risikogruppen } \\
\text { BCG-geimpfte Kinder }\end{array}$ \\
\hline
\end{tabular}

Tab. 2 Tuberkulin-Hauttest (THT): Interventions-cut-offs zur Interpretation des Indurationsdurchmessers (nach $[43,44])$. nach BCG-Impfung falsch positiv ausfallen (geringe Spezifität) [45]. Die BCG-Impfung spielt in Deutschland vor allem bei Immigrantenkindern noch eine Rolle, NTM-Infektionen sind jedoch vor allem bei Kleinkindern häufig. Auf der anderen Seite kommen falsch-negative Ergebnisse bei immunsupprimierten oder schwer kranken Kindern, aber auch kurz nach Impfungen mit Lebendimpfstoffen (Masern, Röteln, Mumps, Windpocken), während oder nach akuten Virusinfektionen vor [44].

\section{In vitro Diagnostik der tuberkulösen Infektion}

Die in den letzten Jahren entwickelten Interferon Gamma Release Assays (IGRAs) ermöglichen eine deutlich spezifischere Diagnose der tuberkulösen Infektion im Kindesalter als der THT [46]. 2 methodisch unterschiedliche IGRAs sind in Deutschland kommerziell erhältlich und zugelassen: QuantiFERON-TB ${ }^{\circledR}$ Gold In-Tube (Cellestis, Australien) und T-SPOT.TB (Oxford Immunotec, England). In diesen In-vitro-Testverfahren wird die IFN$\gamma$-Produktion durch aktivierte T-Zellen nach Stimulation mit tuberkulosespezifischen Antigenen gemessen. Diese Antigene (ESAT-6, CFP-10, TB 7.7) werden von allen Stämmen des Mycobacterium tuberculosis-Komplex (Mycobacterium tuberculosis, Mycobacterium bovis, Mycobacterium africanum, Mycobacterium microti, Mycobacterium canetti), jedoch nicht von BCG-Impfstämmen sowie den häufig bei Kindern vorkommenden NTM wie Mycobacterium avium produziert. Dies bedingt die hohe Spezifität der Tests. Kreuzreaktivität verursachende Ausnahmen sind einige wenige NTM (Mycobacterium kansasii, Mycobacterium szulgai, Mycobacterium marinum und Mycobacterium flavescens), die jedoch im Kindesalter eher eine geringe Rolle spielen. Wie der THT können die IGRAs nicht zwischen tuberkulöser Infektion und Erkrankung unterscheiden. IGRAs besitzen bei immunkompetenten Erwachsenen und Kindern eine ähnliche Sensitivität, aber eine deutlich höhere Spezifität als der THT [46 - 49]. Bei immunsupprimierten, HIV-infizierten Personen ist die Sensitivität der IGRAs dem THT deutlich überlegen [50]. Die Daten für Kinder sind weiterhin limitiert, aber auch hier scheint die Sensitivität der IGRAs, v.a. des T SPOT.TB, in Risikogruppen wie HIV-infizierten und unterernährten Kindern dem THT überlegen [51,52]. Im Gegensatz zum THT zeichnen sich die IGRAs durch ihre Unterscheidungsfähigkeit zwischen Infektionen durch Mycobacterium tuberculosis (THT und IGRA positiv) versus NTM (THT positiv, IGRA negativ) aus [48]. Der Stellenwert der Tests für die Diagnose der aktiven Tuberkulose, vor allem bei sehr jungen oder schwer kranken Kindern, ist bislang unklar.

IGRAs korrelieren besser mit einem Expositionsrisiko als der THT sowie, wie die Ergebnisse einer aktuellen deutschen Studie annehmen lassen, mit dem Risiko der Entwicklung einer manifesten Tuberkulose [53,54]. Fast zeitgleich erschienene Daten aus Gambia zum prädiktiven Vorhersagewert zeigen jedoch keine signifikanten Unterschiede zwischen IGRA und THT bezüglich des Erkrankungsrisikos tuberkuloseexponierter Personen [55]. Dies lässt vermuten, dass Einsatz und Interpretation der IGRAs, genauso wie die des THT, von dem epidemiologischen Umfeld abhängen, in dem der Test durchgeführt wird.

Aufgrund der vorliegenden Studienergebnisse und nach KostenNutzen-Analysen werden IGRAs mittlerweile in vielen westlichen Industrieländern für die Diagnostik der tuberkulösen Infektion empfohlen [56-61]. Die Empfehlungen variieren jedoch in verschiedenen Punkten, wie z.B. dem Einsatz der Tests im Kindesalter. In Deutschland wird seit 2007 für Erwachsene und Kinder ein stufenweises Testverfahren empfohlen: um die diagnostische Spezifität zu erhöhen, sollte ein positiver THT durch einen der beiden IGRAs bestätigt werden. Fällt der IGRA ebenfalls positiv aus, liegt eine Infektion mit Mycobacterium tuberculosis vor, die nach dem Ausschluss einer aktiven Tuberkulose präventiv behandelt werden sollte [60] ${ }^{1}$. In Frankreich und Kanada sind die IGRAs aufgrund der unzureichenden Datenlage noch nicht für Kinder empfohlen [58,61].

Je nach Risikoprofil der zu untersuchenden Person eignen sich die IGRAs bei bestimmten Fragestellungen zur Erhöhung der diagnostischen Sensitivität oder Spezifität ( $\bullet$ Tab.3) [40]. Bei Kindern mit hohem Risiko für eine aktive Tuberkulose sollte ein IGRA daher zusätzlich zum THT durchgeführt werden. In solchen Fällen sollte dann jeder positive Test (THT oder IGRA) als Hinweis auf eine spezifische Infektion gewertet werden. Bei immunkompetenten Kindern mit niedrigem Infektionsrisiko schließt ein negativer IGRA bei gleichzeitig positivem THT eine Infektion hingegen weitgehend aus.

Das Ergebnis eines IGRAs sollte daher immer im Kontext des individuellen Risikos gesehen und interpretiert werden. Die Tests sollten außerdem in einem erfahrenen Labor durchgeführt werden. Da es sich um eine Untersuchung vitaler Zellen handelt, ist es wichtig, die Proben innerhalb des von den Herstellern empfohlenen Zeitrahmens ins Labor zu schicken [62,63].

Ungeklärt ist noch, inwieweit sich IGRAs zur Kontrolle des Therapieerfolges nach Abschluss einer antituberkulösen Chemotherapie oder zur Diagnose bei fraglicher Re-Infektion nach vorheriger Infektion oder Erkrankung eignen.

\section{Diagnose der Tuberkulose}

Bei Nachweis einer tuberkulösen Infektion oder beim Vorhandensein von verdächtigen Symptomen muss eine klinisch manifeste Tuberkulose in jedem Falle ausgeschlossen werden. Zur primären Standarddiagnostik gehört eine Thorax-Röntgenaufnahme in 2 Ebenen bzw. die bildgebende Darstellung fraglich betroffener Organe.

Der Goldstandard für die Diagnose einer Tuberkulose ist der kulturelle Nachweis von Mycobacterium tuberculosis. Mittels moderner Flüssigmedien können positive Ergebnisse bereits nach 1-2 Wochen vorliegen $[64,65]$. Bei jedem positiven Erstisolat muss obligat eine Resistenztestung durchgeführt werden.

\footnotetext{
${ }^{1}$ Leider wird die Durchführung eines IGRA in Deutschland bisher nicht von den Krankenkassen übernommen („IGEL-Leistung“).
} 
Zur Erhöhung der diagnostischen

\section{Sensitivität}

Kinder mit hohem Infektionsrisiko:

bei Verdacht auf akut lebensbedrohliche Tuberkulose Anergie im THT bei starkem Verdacht auf eine tuberkulöse Infektion

exponierte Neugeborene/Säuglinge

vor Organtransplantation

vor dem Gebrauch von Immunsuppressiva wie

TNF- $\alpha$-Inhibitoren

(In diesen Sonderfällen sollte ein IGRA zusätzlich zum

THT durchgeführt und ein positives Ergebnis zu einem

der Tests als Zeichen einer Infektion gewertet werden)

\section{Spezifität}

Kinder mit geringem Risiko für eine tuberkulöse Infektion:

Ausschluss einer tuberkulösen Infektion bei Kindern mit positiven THT und unklarer oder ohne Expositionsanamnese (niedriges Risiko)

Diskriminierung zwischen Infektion Mycobacterium tuberculosis versus NTM
Tab. 3 Besondere Indikationen zur Durchführung eines Interferon- $\gamma$ Release-Assays (IGRA) [40].
Für die Mykobakterienkultivierung werden Sputum oder bei Säuglingen und Kleinkindern Nüchternmagensaft gewonnen. Durch Inhalation mit hochprozentiger Kochsalzlösung induziertes Sputum ist eine geeignete, gut reproduzierbare, auch bei Säuglingen anwendbare Alternative zur Gewinnung von Magensaft [66]. Ggf. ist eine diagnostische Bronchoskopie und bronchoalveoläre Lavage (BAL) indiziert. Aufgrund der im Kindesalter meist paucibazillären Tuberkulose liegt die Sensitivität für den mikroskopischen Nachweis von säurefesten Mykobakterien mittels Ziehl-Neehlsen-Färbung mit 10-15\% deutlich unter der Sensitivität bei Erwachsenen (20-80\%, im Durchschnitt ca. $60 \%$ ) [67,68]. Dennoch sollte der färberische Nachweis immer versucht werden, vor allem bei älteren Kindern, die eine kavernöse, ,adult-type“-Tuberkulose mit hohen Bakterienzahlen aufweisen können. Der kulturelle Nachweis von Mycobacterium tuberculosis gelingt bei Kindern mit Verdacht auf pulmonale Tuberkulose nur in ca. 30-40\%, bei Kindern mit ausgedehnter Lungentuberkulose (z.B. Lymphknoteneinbruch) jedoch in bis zu $70 \%[67,69]$.

Bei Verdacht auf extrapulmonale Tuberkulose sollte für die Mykobakterienkultur nach Möglichkeit Material vom Ort der vermuteten Infektion entnommen und bakteriologisch sowie ggf. histologisch untersucht werden (z.B. Liquor, Gelenkpunktat, Knochenmark, Biopsiematerial).

Nukleinsäureamplifikationstechniken (NAT) wie die Polymerasekettenreaktion (PCR) erlauben bei Verdacht eine schnellere Diagnose als die Mykobakterienkultur und ermöglichen die Unterscheidung zwischen Mycobacterium tuberculosis und NTM. Die Sensitivität sowie der negative prädiktive Wert schwanken jedoch stark und hängen von dem untersuchten Material sowie der angewandten Methode ab [70]. Laborkontaminationen sind häufig. Die Sensitivität und Spezifität serodiagnostischer Tests für Tuberkulose ist bislang unzureichend [71].

\section{Prävention und Management der Tuberkulose $\nabla$}

Die WHO hat 2006 Empfehlungen für das Management der Tuberkulose im Kindesalter veröffentlicht, die als Grundlage für die Entwicklung nationaler Tuberkulose-Richtlinien dienen sollen [72]. Diese Empfehlungen richten sich jedoch überwiegend an einkommensschwache Länder mit einer mittleren bis hohen Tuberkuloseinzidenz. In den westlichen Industrieländern mit niedrigen Inzidenzen bedarf es einer Anpassung dieser Empfehlungen in Bezug auf Umgebungsuntersuchungen, zur Verfügung stehender Diagnostika sowie die Empfehlungen für präventive Chemotherapie [40,73].

\section{Prävention}

Eine effektive Schutzimpfung gegen Tuberkulose wäre als Präventionsmaßnahme wünschenswert. Die Angaben zur präventiven Wirksamkeit der BCG-Impfung schwanken zwischen 0-80\% mit einem Durchschnitt von 50\% [74]. Die Hauptwirkung der Impfung liegt im Schutz vor disseminierter Tuberkulose (Meningitis tuberculosa und Miliartuberkulose) bei Säuglingen und Kleinkindern, weniger in der Prävention einer Infektion und pulmonaler Tuberkulose [74-76]. Die postnatale Impfung wird überwiegend für Länder mit einer hohen Tuberkuloseinzidenz und auch noch in einigen europäischen Ländern empfohlen [77]. In Deutschland wird die BCG-Impfung aufgrund von ungünstigen Nutzen-Risikoanalysen seit 1998 nicht mehr empfohlen [78].

Das wichtigste Ziel präventiver Maßnahmen in einem Tuberkulose-Niedriginzidenzland wie Deutschland bleibt daher, neben der raschen Auffindung infektiöser Erkrankter, die frühe Erkennung und Behandlung der tuberkulösen Primärinfektion (LTBI). Die Tuberkulose ist in Deutschland eine nach dem Infektionsschutzgesetz meldepflichtige Erkrankung. Nicht gemeldet wird die tuberkulöse Infektion oder Infektionen mit NTM. Nach Meldung einer an Tuberkulose erkrankten Person initiiert die zuständige Gesundheitsbehörde eine Umgebungsuntersuchung. Auf diesem Weg können die meisten infizierten bzw. bereits erkrankten Kinder frühzeitig diagnostiziert werden.

\section{Infektionsprävention: Expositionsprophylaxe}

Kinder unter 5 Jahren mit gesicherter Exposition sollten in jedem Fall frühzeitig prophylaktisch mit Isoniazid (INH) behandelt werden, auch wenn der initiale THT negativ ausfällt [60]. Diese Maßnahme dient der Verhinderung einer Infektion bzw. des Fortschreitens einer frischen Infektion zu einer Erkrankung. Je nach Risikoprofil sollte ggf. auch bei Kindern zwischen 5-15 Jahren eine Expositionsprophylaxe in Erwägung gezogen werden. Nach 3 Monaten muss der THT und/oder ein IGRA wiederholt werden. Bleibt der Test negativ, kann die Prophylaxe beendet werden. Zu diesem Zeitpunkt sollte auch der Indexfall effektiv behandelt sein und negative Kulturen aufweisen. Jeder positive Test (THT oder IGRA) nach 3-monatiger Chemoprophylaxe ist als Konversion und Ausdruck der Infektion zu werten und die Behandlung sollte, nach Ausschluss einer aktiven Tuberkulose, für weitere 6 Monate entsprechend der Chemoprävention der LTBI fortgesetzt werden.

Ein klassischer Fall für die Expositionsprophylaxe ist das Neugeborene einer Mutter mit infektiöser Tuberkulose. Unter der Voraussetzung, dass die Mutter effektiv behandelt wird, das Kind eine Chemoprophylaxe erhält, hygienische Standards gewähr- 
Tab.4 Medikamente der ersten Wahl zur Behandlung der Tuberkulose [nach [40]).

\begin{tabular}{|c|c|c|}
\hline Medikament & Dosis & Hauptnebenwirkungen und Monitoring \\
\hline $\begin{array}{l}\text { Isoniazid (INH) } \\
\text { entspricht ca. } \\
0-5 \text { Jahre } \\
6-9 \text { Jahre } \\
10-14 \text { Jahre } \\
15-18 \text { Jahre }\end{array}$ & $\begin{array}{l}200 \mathrm{mg} / \mathrm{m}^{2} \mathrm{KO} \\
8-10 \mathrm{mg} / \mathrm{kgKG} \\
7-8 \mathrm{mg} / \mathrm{kgKG} \\
6-7 \mathrm{mg} / \mathrm{kgKG} \\
5-6 \mathrm{mg} / \mathrm{kgKG} \\
\max .300 \mathrm{mg} / \text { Tag }\end{array}$ & $\begin{array}{l}\text { INH Hepatitis in ca. } 0,44 \% \text { nach Beginn der Behandlung, dosisabhängige periphere } \\
\text { Neurotoxizität. } \\
\text { Sehr selten: fatale primäre Hepatopathie } \\
\text { Monitoring: Leberfunktion (Transaminasen) 2, 4, } 8 \text { Wochen nach Beginn der Therapie, } \\
\text { v. a. bei Patienten mit bekannter Lebererkrankung oder bei Symptomen } \\
\text { Vitamin B6 (Pyridoxin) Supplementierung bei Kleinkindern und dystrophen Kindern } \\
(10-15 \text { mg/Tag) }\end{array}$ \\
\hline $\begin{array}{l}\text { Rifampicin (RMP) } \\
\text { entspricht ca. } \\
0-5 \text { Jahre } \\
6-9 \text { Jahre } \\
10-14 \text { Jahre } \\
15-18 \text { Jahre }\end{array}$ & $\begin{array}{l}350 \mathrm{mg} / \mathrm{m}^{2} \mathrm{KO} \\
15 \mathrm{mg} / \mathrm{kgKG} \\
12 \mathrm{mg} / \mathrm{kgKG} \\
10 \mathrm{mg} / \mathrm{kgKG} \\
10 \mathrm{mg} / \mathrm{kgKG} \\
\text { max. } 600 \mathrm{mg} / \mathrm{Tag}\end{array}$ & $\begin{array}{l}\text { Pruritus, meist selbstlimitierend. Hepatopathie in ca. 0,5\%, besonders bei Beginn } \\
\text { der Behandlung. Orange Färbung der Körperflüssigkeiten (Urin, Sputum, Tränen), } \\
\text { über die die Eltern aufgeklärt werden sollten. } \\
\text { Monitoring der Leberfunktion 2, 4, } 8 \text { Wochen nach Beginn der Therapie, v. a. bei } \\
\text { Patienten mit bekannter Lebererkrankung. } \\
\text { Cave: Starker Enzyminduktor. Wirkungsminderung folgender Medikamente ist } \\
\text { möglich: Antikonvulsiva, Azidothymidin, Theophyllin, Antikoagulanten des Cumarin- } \\
\text { Typs, Kontrazeptiva, orale Antidiabetika, Digitoxin, Propanolol, Cyclosporin etc. }\end{array}$ \\
\hline Pyrazinamid (PZA) & $\begin{array}{l}30 \mathrm{mg} / \mathrm{kgKG} / \mathrm{Tag} \\
\max . \mathrm{TD} \\
1,5 \mathrm{~g}(70 \mathrm{kgKG}) \\
2 \mathrm{~g}(>70 \mathrm{kgKG})\end{array}$ & $\begin{array}{l}\text { Asymptomatische, nicht interventionsbedürftige Hyperurikämie häufig. Gelenk- } \\
\text { schmerzen, besonders bei Beginn der Behandlung. Gastrointestinale Symptome } \\
\text { häufig. Akute Hepatitis in ca. 0,5\% der Patienten. } \\
\text { Monitoring: Transaminasen bei Patienten mit bekannter Lebererkrankung (s. INH). }\end{array}$ \\
\hline $\begin{array}{l}\text { Ethambutol (EMB) } \\
\text { entspricht ca. } \\
0-5 \text { Jahre } \\
>5 \text { Jahre }\end{array}$ & $\begin{array}{l}850 \mathrm{mg} / \mathrm{m}^{2} \mathrm{KO} \\
30 \mathrm{mg} / \mathrm{kgKG} \\
25 \mathrm{mg} / \mathrm{kgKG} \\
\text { max. TD } 1,75 \mathrm{~g}\end{array}$ & $\begin{array}{l}\text { Optikusneuritis mit Einschränkung der Sehschärfe und des Rot-Grün-Sehens } \\
\text { Monitoring: Augenärztliche Untersuchung vor, während und nach der Therapie (für } \\
\text { Kleinkinder spezielle Farbtafeln benutzen), regelmäßige Symptomabfrage während } \\
\text { der Therapie. }\end{array}$ \\
\hline Streptomycin (SM) & $\begin{array}{l}20 \mathrm{mg} / \mathrm{kg} / \mathrm{KG} / \mathrm{Tag} \text {, } \\
\text { i. m. oder i.v. } \\
\text { max. TD } 0,75 \mathrm{~g} \text {; } \\
\text { Therapie-Gesamtdosis: } \\
30 \mathrm{~g} / \mathrm{m}^{2} \mathrm{KO}\end{array}$ & $\begin{array}{l}\text { Ototoxizität (N. acusticus und N. vestibularis) } \\
\text { Selten: Neurotoxizität, Nephrotoxizität. } \\
\text { Monitoring: Hörtests vor, während und nach der Therapie. Regelmäßige Symptom- } \\
\text { abfrage. Kreatininwert vor Beginn der Behandlung }\end{array}$ \\
\hline
\end{tabular}

leistet sind und die Mutter bis zur Sputumnegativierung einen Mund-Nasenschutz trägt, ist eine Trennung von Mutter und Kind nicht unbedingt erforderlich. Eine antituberkulotische Behandlung der Mutter stellt keine Kontraindikation für das Stillen dar. Bei extrem hoher Infektiosität der Mutter oder medikamentenresistenter Tuberkulose kann zu diesem Vorgehen primär nicht geraten werden.

\section{Therapie der LTBI: Chemoprävention}

Die Therapie der LTBI dient der Prävention einer Erkrankung und wird in Deutschland sowie den meisten westlichen Industrieländern für alle Kinder ( 0 - 15 Jahre) empfohlen [43,44,57]. Die beste präventive Wirksamkeit wird mit einer Behandlung mit INH über 9 Monate erreicht, die in Deutschland und den USA empfohlen wird $[43,44,79,80]$. Einige Länder sowie die WHO empfehlen einen kürzeren Behandlungszeitraum von 6 Monaten, der wahrscheinlich in vielen Fällen ebenfalls ausreichend ist $[57,72]$. Eine anscheinend effektive Alternative ist die kombinierte Gabe von INH und RMP über 3 Monate, die aufgrund der verkürzten Therapiedauer die Compliance deutlich verbessert [81 - 84]. Die Eltern sollten zu Beginn der Behandlung über mögliche Symptome einer Tuberkulose aufgeklärt werden. Folgeuntersuchungen einschließlich Thoraxröntgenuntersuchung sollten nach 3 Monaten, zum Ende der Chemoprävention sowie 1 -2 Jahre nach Beendigung der Chemoprävention stattfinden.

\section{Therapie der Tuberkulose: Chemotherapie}

Zur Behandlung der medikamentensensiblen Tuberkulose stehen INH, Rifampicin (RMP), Pyrazinamid (PZA), Ethambutol (EMB) und Streptomycin (SM) als Erstrangmedikamente zur Verfügung, die in Kombination sterilisierend und teilweise auch bakterizid auf sich unterschiedlich schnell vermehrende Keime wirken.

Aufgrund der Verteilungsvolumina ist die Dosierung nach Körperoberfläche im Kindesalter am exaktesten, alternativ kann nach Kilogramm Körpergewicht (kg/KG) dosiert werden [85, 86]. Wichtig ist es, die Kinder im Verlauf der Behandlung regelmäßig zu wiegen und ggf. die Dosierungen anzupassen ( Tab.4).

Die Dauer der anitituberkulotischen Chemotherapie richtet sich nach der Lokalisation und dem Schweregrad der Erkrankung ( Tab.5). Falls kein kultureller Nachweis bei Kindern gelingt, sollte entsprechend dem Resistenzprofil des Indexfalles behandelt werden. Die Therapie besteht aus einer 2-monatigen Initialphase, in der INH, RMP, PZA und bei komplizierteren Formen zusätzlich EMB (orale Gabe möglich) oder SM gegeben werden. In einer Fortsetzungsphase, die bei unkomplizierter Tuberkulose 4, bei komplizierten Formen 7 Monate und bei der Meningitis tuberculosa 9 Monate dauert, wird mit INH und RMP behandelt (Gesamtbehandlungsdauer 6-12 Monate, Tab.5). Beim Vorliegen von extrapulmonalen Tuberkuloseformen sollten ggf. entsprechende Organspezialisten hinzugezogen werden.

Bei der Meningitis tuberculosa kann EMB durch Protionamid ersetzt werden, das eine bessere Liquorgängigkeit zeigt $[88,89]$. Alternativ steht SM parenteral zur Verfügung. Bei Vorliegen 


\section{Manifestation}

unkomplizierte pulmonale Tuberkulose periphere Lymphknotentuberkulose komplizierte pulmonale Tuberkulose extrapulmonale Tuberkulose „Adult-Type“" Tuberkulose Knochen-, Gelenkstuberkulose disseminierte/Miliartuberkulose konnatale Tuberkulose

Meningitis tuberculosa
Therapiedauer

6 (9 bei HIV-Infektion)

6

alternativ

9

$6-9$

6-9

$9-12$
Initial- und Fortsetzungsphase

2 INH/RMP/PZA, 4 (7) INH/RMP

2 INH/RMP/PZA/EMB, 4 INH/RMP

2 INH/RMP/PZA, 7 INH/RMP

2 INH/RMP/PZA/EMB, 4 INH/RMP

2 INH/RMP/PZA/EMB, 4 - 7 INH/RMP

$2-3$ INH/RMP/PZA/EMB oder SM, 7-9 INH/RMP
Tab. 5 Therapiedauer (in Monaten), abhängig von der Manifestationsform (nach $[40,74,86]$ ). eines kommunizierenden Hydrozephalus können Furosemid und Azetazolamid gegeben werden, ein nicht-kommunizierender Hydrozephalus ist ein Notfall und bedarf der Anlage eines ventrikulo-peritonealen Shunts [75].

Der zusätzliche Nutzen von Steroiden in der Initialphase konnte für die Meningitis tuberculosa und die tuberkulöse Perikarditis gezeigt werden, während er für die Miliartuberkulose nicht eindeutig belegt ist $[35,87,90]$. Bei der Meningitis tuberculosa sollte aufgrund der guten Liquorgängigkeit Dexamethason $(0,6 \mathrm{mg} /$ $\mathrm{kg} / \mathrm{Tag})$ gegeben werden, ansonsten ist Prednisolon $(2 \mathrm{mg} / \mathrm{kg} /$ Tag) geeignet [32,87,91,92].

Bei Atemwegsobstruktion, verursacht durch vergrößerte Lymphknoten, kann ebenfalls initial mit Prednisolon behandelt werden. Hier ist die Datenlage jedoch unklar [93]. Bei unzureichender klinischer Besserung oder bei schwerer Atemwegsobstruktion und Verdacht auf Lymphknoteneinbruch ist eine Bronchoskopie zur Entfernung von käsigem Material indiziert, in lebensbedrohlichen Fällen eine chirurgische Enukleation von stark vergrößerten Lymphknoten.

Das Vorliegen von neurologischen Symptomen oder Wirbelsäuleninstabilität bei der spinalen Tuberkulose bedarf ggf. einer frühen chirurgischen Intervention [94].

Den Eltern fällt während der viele Monate dauernden ambulanten Therapie der Tuberkulose die wichtige Aufgabe der Therapieüberwachung zu. Bei Verdacht auf Non-Compliance muss eine direkt überwachte Therapie (DOT) in Erwägung gezogen werden [87]. Die Isolation eines Kindes zum Infektionsschutz ist besonders beim Vorliegen einer mikroskopisch positiven Tuberkulose notwendig. Der Besuch einer Betreuungseinrichtung ist erlaubt, wenn nach ärztlichem Urteil keine Ansteckungsgefahr mehr besteht (bei primär mikroskopischem Nachweis nach ca. 2-3 Wochen Therapie).

\section{Follow-up und Monitoring}

Folgeuntersuchungen sind nach 1, 2 Monaten, zum Therapieende und dann bei unauffälliger Klinik 12-monatlich über 2 Jahre sinnvoll [40]. Falls initial positiv, sollten Kulturen bis zur Sputumnegativierung alle 2 Monate wiederholt werden, bei zweifelhaftem Ansprechen häufiger.

Die antituberkulotischen Medikamente werden von Kindern im Vergleich zu Erwachsenen gut vertragen. Das Risiko einer durch INH, RMP oder PZA induzierten Hepatitis ist sehr niedrig ( $\checkmark$ Tab.4) $[95,96]$. Eine durch EMB verursachte Optikusneuritis mit visuellen Störungen kommt bei Kindern extrem selten vor [85].

Vor Beginn der Behandlung sollte eine Kontrolle von Blutbild, Nieren- und Leberfunktion erfolgen, bei der Gabe von EMB zusätzlich ein Farbsehtest bzw. ophthalmologische Augenhintergrunduntersuchungen. Im Verlauf sollte gezielt nach möglichen
Nebenwirkungen gefragt und untersucht werden. Kontrollen der Blutwerte sind vor allem bei Vorliegen von Leber- oder Nierenfunktionsstörungen notwendig. Farbseh- und Hörtests sollten bei der Gabe von EMB bzw. SM monatlich durchgeführt werden. Innerhalb der ersten 2-3 Monate unter antituberkulotischer Therapie kann es durch Immunrekonstitution bei Antigenpersistenz zu einer reaktiven Vergrößerung betroffener Lymphknoten kommen. Intrazerebrale Tuberkulome können sich ebenfalls vergrößern bzw. sogar neu entstehen. In diesen Fällen ist häufig eine prolongierte Behandlung mit Kortikosteroiden indiziert [97]. Bei unzureichendem Ansprechen ist in Einzelfällen und unter Einbeziehung eines Spezialisten ein Therapieversuch mit Thalidomid sinnvoll [98]. Wenn diese Befunde im weiteren Verlauf nicht rückläufig sind, muss ein Therapieversagen (z. B. Medikamentenresistenz, Malabsorption) ausgeschlossen werden.

\section{Sonderfall - Medikamentenresistente Tuberkulose}

Daten zur präventiven Behandlung und Chemotherapie bei Medikamentenresistenz im Kindesalter sind kaum vorhanden. Kinder mit Kontakt zu oder Verdacht auf medikamentenresistente Tuberkulose sollten daher nach Möglichkeit von Spezialisten betreut werden.

Neben dem Nachweis eines resistenten Mycobacterium-tuberculosis-Stammes sollte eine Medikamentenresistenz in den folgenden Fällen vermutet werden [75]:

- Kinder mit Kontakt zu einer Person mit medikamentenresistenter Tuberkulose

- Kinder mit unzureichendem Ansprechen auf eine Behandlung mit Erstrangmedikamenten

- Bei Reaktivierung einer Tuberkulose nach unvollständiger Behandlung

Amikacin, Fluorchinolone (sind im Kindesalter in Deutschland nicht zugelassen), Para-Aminosalizylsäure, Cycloserin/Terizidon, Protionamid, Linezolid und Capreomycin stehen als Zweitrangmedikamente zur Behandlung zur Verfügung [40]. Viele dieser Medikamente sind nicht für die Anwendung im Kindesalter evaluiert und ihr Einsatz ist wegen möglicher Nebenwirkungen begrenzt. Die Erfahrungen und Dosierungsangaben basieren meist auf Expertenempfehlungen. Dennoch kann die probate Behandlung einer medikamentenresistenten Tuberkulose unter diesen Umständen lebensrettend sein.

\section{Chemoprävention}

Bei Kindern mit Kontakt zu einer MDR-Tuberkulose ist eine Chemoprävention mit INH wirkungslos [100]. Basierend auf Expertenempfehlungen sollte stattdessen mit 2 Medikamenten, die bei dem Indexfall als sensibel getestet sind, für mindestens 6 Monate behandelt und über 1-2 Jahre nachbeobachtet werden [43]. 
Bei Kontakt zu einer Person mit INH-Monoresistenz kann alternativ RMP über 4-6 Monate unter strenger Überwachung der Compliance gegeben werden [44,57].

\section{Chemotherapie}

Bei nachgewiesener MDR-Tuberkulose (bei der Kontaktperson und/oder dem Kind) muss initial für 6 Monate mit mindestens 4 wirksamen Medikamenten, einschließlich eines Fluorchinolons sowie eines der injizierbaren Medikamente, behandelt werden [87]. In der Fortsetzungsphase sollten 3 der Medikamente gegeben werden. Durch das Wegfallen wichtiger Standardmedikamente verlängert sich die Therapiedauer bei MDR-Tuberkulose je nach Schweregrad auf 18-24 Monate nach Erhalt der ersten negativen Kultur.

Bei entsprechender Verträglichkeit kann zusätzlich INH bei MDR-Tuberkulose in hoher Dosierung (bis $18 \mathrm{mg} / \mathrm{kg}$ ) trotz INHResistenz in Erwägung gezogen werden, da bei Erwachsenen damit ein verbesserter Therapieerfolg nachgewiesen wurde [100]. Bei der Therapie der medikamentenresistenten Tuberkulose ist eine engmaschige Verträglichkeitskontrolle unbedingt erforderlich.

\section{Zusammenfassung}

Trotz der positiven epidemiologischen Entwicklung in Hinblick auf die Tuberkulose in Deutschland ist die Kenntnis der Besonderheiten dieses Krankheitsbildes im Kindesalter von Bedeutung. Die Erkrankung bei Kindern ist ein Indikator für die Übertragungsrate innerhalb der Gesellschaft. Die Kindertuberkulose unterscheidet sich in ihrer klinischen Präsentation, aber auch unter speziellen diagnostischen und therapeutischen Aspekten von der Erwachsenentuberkulose. Kinder haben ein besonders hohes Risiko an Tuberkulose zu erkranken, die frühe Diagnose und Therapie der Infektion oder Erkrankung sind daher von grundlegender Bedeutung.

\section{Literatur}

1 Dolin PJ, Raviglione MC, Kochi A. Global tuberculosis incidence and mortality during 1990-2000. Bull World Health Organ 1994; 72: $213-220$

2 Rekha B, Swaminathan S. Childhood tuberculosis - global epidemiology and the impact of HIV. Ped Respir Rev 2007; 8: 99-106

3 Jereb JA, Kelly GD, Porterfield DS. The epidemiology of tuberculosis in children. Sem Pediatr Infect Dis 1993; 4: 220-231

4 Nelson LJ, Wells CD. Global epidemiology of childhood tuberculosis. Int J Tuberc Lung Dis 2004; 8: 636-647

5 World Health Organization. Global Tuberculosis Control: Surveillance, Planning, Financing: WHO report 2008. Geneva: World Health Organization (WHO/HTM/TB/2008.393), 2008

6 Clancy L, Rieder HL, Enarson DA et al. Tuberculosis elimination in the countries of Europe and other industrialized countries. Eur Respir J 1991; 4: $1288-1295$

7 Robert Koch-Institut. Bericht zur Epidemiologie der Tuberkulose in Deutschland für 2006. Berlin: Robert Koch-Institut, 2008

8 World Health Organization. Anti-Tuberculosis Drug-Resistance in the World. Report No.4. Geneva: World Health Organization (WHO/ HTM/TB/2008.394), 2008

9 World Health Organization. Extensively drug-resistant tuberculosis (XDR-TB): Recommendations for prevention and control. Wkly Epidemiol Rec 2006; 81: 430-432

10 Cardona M, Bek MD, Mills K et al. Transmission of tuberculosis from a seven-year-old child in a Sydney school. J Paediatr Child Health 1999; 35: $375-378$

11 Donald PR, Fourie PB, Grange JM. Tuberculosis in childhood. JL van Schalk Publishers, 1999
12 Loudon RG, Spohn SK. Cough frequency and infectivity in patients with pulmonary tuberculosis. Am Rev Respir Dis 1969; 99: 109-111

13 Corbett EL, Watt CJ, Walker $N$ et al. The growing burden of tuberculosis. Global Trends and Interactions with the HIV Epidemic. Arch intern Med 2003; 163: 1009-1021

14 Aaron L, Saadoun D, Calantroni I et al. Tuberculosis in HIV-infected patients: a comprehensive review. Clin Microbiol Infect 2004; 10: $388-398$

15 Marais BJ, Gie RP, Schaaf HS et al. The Natural History of childhood intra-thoracic tuberculosis: a critical review of literature from the prechemotherapy era. Int J Tuberc Lung Dis 2006; 8: 392 - 402

16 Schlossberg $D$. Tuberculosis and nontuberculous mycobacterial infections. Fifth Edition. McGraw-Hill Companies, 2006

17 Jacobsen $M$, Detjen A, Mueller $H$ et al. Clonal expansion of CD8+ effector T cells in childhood tuberculosis. J Immunol 2007; 179: 1331 1339

18 Casanova J-L, Abel L. The Human Model: A genetic dissection of immunity to infection in natural conditions. Nature Reviews Immunology 2004; 4: 55-66

19 Ulrichs T, Kaufmann SHE. Immunology and Persistence. Issues Infect Dis 2003; 2: $112-127$

20 Feja K, Saiman L. Tuberculosis in children. Clin Chest Med 2005; 26 : $295-312$

21 Marais BJ, Gie RP, Schaaf HS et al. A proposed radiological classification of childhood intra-thoracic tuberculosis. Pediatr Radiol 2004; 34: 886- 894

22 Cruz AT, Starke JR. Clinical manifestations of tuberculosis in children. Paed Respir Rev 2007; 8: 107-117

23 Romanus $V$, Hallander $H$, Wahlen $P$ et al. Atypical mycobacteria in extrapulmonary disease among children. Incidence in Sweden from 1969 to 1990 , related to changing BCG-vaccination. Tuber Lung Dis 1995; 76: $300-310$

24 Wiese-Posselt M, Siedler A, Rademacher A et al. ESPID-Study-Group 2: incidence of nontuberculous mycobacteria (NTM) in children aged $<15$ years, Germany 2002-2004. Tampere, Finland: ESPID Annual Meeting, May 2004

25 Haverkamp MH, Arend SM, Lindeboom JA et al. Nontuberculous mycobacterial infection in children: A 2-year prospective surveillance study in the Netherlands. Clin Infect Dis 2004; 39: 450-456

26 Thegerström J, Friman V, Nylen 0 et al. Clinical features and incidence of Mycobacterium avium infections in children. Scand J Infect Dis 2008; 40: 481 - 486

27 Lindeboom JA, Kuijper EJ, Bruijnesteijn van Coppenraet ES et al. Surgical excision versus antibiotic treatment for nontuberculous mycobacterial cervicofacial lymphadenitis in children: A Multicenter, Randomized, Controlled Trial. Clin Infect Dis 2007; 44: 1057 - 1064

28 Griffith DE, Aksamit T, Brown-Elliott BA et al. An official ATS/IDSA statement: Diagnosis, treatment, and prevention of nontuberculous mycobacterial diseases. Am J Respir Crit Care Med 2007; 175: 367 416

29 Wallgren A. The time-table of tuberculosis. Tubercle 1948; 29: 245 25

30 Schoeman J, Mansvelt E, Springer $P$ et al. Coagulant and fibrinolytic status in tuberculous meningitis. Pediatr Infect Dis J 2007; 26: $428-431$

31 Medical Research Council Streptomycin in Tuberculosis Trials Committee. Streptomycin treatment in tuberculous meningitis. Lancet 1948; 1: $582-597$

32 Rock RB, Olin M, Baker CA et al. Central nervous system tuberculosis: pathogenesis and clinical aspects. Clin Microbiol Rev 2008; $21: 243$ 261

33 Schoeman JF, Van Zyl LE, Laubscher JA et al. Serial CT scanning in childhood tuberculous meningitis: prognostic features in 198 cases. J Child Neurol 1995; 10: 320-329

34 Schoeman J, Wait J, Burger $M$ et al. Long-term follow up of childhood tuberculous meningitis. Dev Med Child Neurol 2002; 44: 522 - 526

35 Sharma SK, Mohan A, Sharma A et al. Miliary Tuberculosis: New Insights Into an Old Disease. Lancet Infect Dis 2005; 5: 415-430

36 Connelly Smith K. Congenital tuberculosis: a rare manifestation of a common infection. Curr Opin Infect Dis 2002; 15: 269-274

37 Cantwell MF, Shehab ZM, Costello AM et al. Congenital Tuberculosis. New Engl J Med 1994; 330: 1051 - 1054

38 Ormerod $P$. Tuberculosis in pregnancy and the puerperium. Thorax 2001: 56: $494-499$ 
39 Ozuah PO, Ozuah TP, Stein REK et al. Evaluation of a risk assessment questionnaire used to target tuberculin skin testing in children. JAMA 2001; 285: $451-453$

40 Magdorf K, Detjen AK. Proposed management of childhood tuberculosis in low-incidence countries. Eur J Pediatr 2008; 167: 927 - 938 Epub 2008 May 10

41 Magdorf $K$. Tuberkulose und nicht-tuberkulöse mykobakterielle Krankheiten. In: DGPI Handbuch, Infektionen bei Kindern und Jugendlichen. 4. Auflage. München: Futuramed Verlag, 2003: 699-719

42 Sagebiel D, Magdorf $K$, Loddenkemper R. Aktuelle Information des DZK zur Tuberkulinversorgung Deutschlands. Pneumologie 2005; 59: $236-237$

43 American Thoracic Society, Centers for Disease Control and Prevention. Targeted tuberculin testing, and treatment of latent tuberculosis infection. Am J Respir Crit Care Med 2000; 161: 221 - 247

44 Magdorf K. Tuberkulose im Kindesalter - Pathogenese, Prävention, Klinik und Therapie. Monatsschr Kinderheilk 2006; 154: 124-132

45 Haimi-Cohen Y. Skin indurations in response to tuberculin testing in patients with nontuberculous mycobacterial lymphadenitis. Clin Infect Dis 2001; 33: 1786 - 1788

46 Pai M, Zwerling A, Menzies D. Systematic review: T-cell-based assays for the diagnosis of latent tuberculosis infection: an update. Ann Intern Med 2008; 149 [Epub ahead of print]

47 Pai $M$, Menzies D. Interferon-gamma release assays: what is their role in the diagnosis of active tuberculosis? Clin Infect Dis 2007; 44: 74 77

48 Detjen AK, Keil T, Roll $S$ et al. Interferon- $\gamma$ release assays improve the diagnosis of tuberculosis and nontuberculous mycobacterial disease in children in a country with a low incidence of tuberculosis. Clin Infect Dis 2007; 45: $322-328$

49 Pai M, Kalantri S, Dheda K. New tools and emerging technologies for the diagnosis of tuberculosis: part I. Latent tuberculosis. Expert review of molecular diagnostics 2006; 6: 413-422

50 Karam F, Mbow F, Fletcher $H$ et al. Sensitivity of IFN-gamma release assay to detect latent tuberculosis infection is retained in HIV-infected patients but dependent on HIV/AIDS progression. PLoS ONE 2008; 3: e1441

51 Liebeschuetz S, Bamber S, Ewer K et al. Diagnosis of tuberculosis in South African children with a T-cell-bases assay: a prospective cohort study. Lancet 2004; 365: $97-98$

52 Mandalakas AM, Hesseling AC, Chegou NN et al. High level of discordant IGRA results in HIV-infected adults and children. Int J Tuberc Lung Dis 2008; 12: $417-423$

53 Menzies D, Pai M, Comstock G. Meta-analysis: new tests for the diagnosis of latent tuberculosis infection: areas of uncertainty and recommendations for research. Ann Intern Med 2007; 146: 350- 354

54 Diel R, Loddenkemper R, Meywald-Walter Ket al. Predictive value of a whole blood IFN-gamma assay for the development of active tuberculosis disease after recent infection with Mycobacterium tuberculosis. Am J Respir Crit Care Med 2008; 177: 1164 - 1170

55 Hill PC, Jackson-Sillah DJ, Fox A et al. Incidence of tuberculosis and the predictive value of ELISPOT and Mantoux tests in Gambian case contacts. PLoS ONE 2008; 3: e1379

56 Mazurek GH, Jereb J, Lobue P et al. Guidelines for using QuantiFERONTB Gold test for detecting Mycobacterium tuberculosis infection, United States. MMWR Recomm Rep 2005; 54: 49- 55

57 National Institute for Health and Clinical Excellence. Tuberculosis: clinical diagnosis and management of tuberculosis, and measures for its prevention and control. Available at: www.nice.org.uk, 2006

58 Haute Autorité de santé. Test de détéction de la production d'interferon- $\gamma$ pour le diagnosis des infection tuberculeuses. Available at: www.has-santé.fr, 2006

59 Diel R, Nienhaus A, Lange $C$ et al. Cost-optimization of screening for latent tuberculosis in close contacts. Eur Respir J 2006; 28: 35-44

60 Diel R, Forssbohm M, Loytved G et al. Empfehlungen für die Umgebungsuntersuchungen bei Tuberkulose. Pneumologie 2007; 61: $440-455$

61 Canadian Tuberculosis Committee. Interferon gamma release assays for latent tuberculosis infection. Canada Communicable Disease Report, 2007

62 Doherty TM, Demissie A, Menzies D et al. VACSEL Study Group. Effect of sample handling on analysis of cytokine responses to Mycobacterium tuberculosis in clinical samples using ELISA, ELISPOT and quantitative PCR. J Immunol Meth 2005; 298: 129-141
63 Meier T, Eulenbruch HP, Wrighton-Smith P et al. Sensitivity of a new commercial enzyme-linked immunospot assay (T SPOT-TB) for diagnosis of tuberculosis in clinical practice. Eur J Clin Microbiol Infect Dis 2005; 24: 529 - 536

64 Dinnes J, Deeks J, Kunst $H$ et al. A systematic review of rapid diagnostic tests for the detection of tuberculosis. Health Technol Assess 2007; 11: 1- 196

65 Rüsch-Gerdes S, Hillemann D. Moderne mykobakteriologische Labordiagnostik. Pneumologie 2008; 62: 533-540

66 Zar HJ, Hanslo D, Apolles P. Induced sputum versus gastric lavage for microbiological confirmation of pulmonary tuberculosis in infants and young children: a prospective study. Lancet 2005; 365: $130-$ 134

67 Starke JR. Pediatric tuberculosis: time for a new approach. Tuberculosis 2003; 5: 594-603

68 Steingart KR, Henry M, Hopewell PC et al. Fluorescence versus conventional sputum smear microscopy for tuberculosis: a systematic review. Lancet Infect Dis 2006; 6: 570-581

69 Marais BJ, Hesseling AC, Gie RP et al. The bacteriologic yield in children with intrathoracic tuberculosis. Clin Infect Dis 2006; 42: 69-71

70 Ling DI, Flores LL, Riley LW et al. Commercial nucleic-acid amplification tests for diagnosis of pulmonary tuberculosis in respiratory specimens: meta-analysis and meta-regression. PLoS ONE 2007; 3 (2): e1536 doi 0.1371/journal.pone.0001536

71 Steingart KR, Henry M, Laal S et al. Commercial serological antibody detection tests for the diagnosis of pulmonary tuberculosis: a systematic review. PLoS Med 2007; 4: e202

72 World Health Organization. Guidance for national tuberculosis programmes on the management of tuberculosis in children. 2006 WHO/HTM/ TB/2006.371

73 Broekmans JF, Migliori GB, Rieder HL et al. European framework for tuberculosis control and elimination in countries with a low incidence. Eur Respir J 2002; 19: 765 - 775

74 Colditz GA, Berkey CS, Mosteller F et al. The efficacy of bacillus Calmette-Guérin vaccination of newborns and infants in the prevention of tuberculosis: meta-analyses of the published literature. Pediatrics 1995; 96: 29-35

75 Davies PDO. Clinical Tuberculosis. Arnold Publishers. Third Edition, 2003

76 Soysal A, Millington KA, Bakir M et al. Effect of BCG vaccination on risk of Mycobacterium tuberculosis infection in children with household tuberculosis contact: a prospective community-based study. Lancet 2005; 366: 1443 - 1451

77 Infuso A, Falzon D. European survey of BCG vaccination policies and surveillance in children, 2005. Euro Surveill 2006; 11: 6-11

78 Ständige Impfkommission am Robert Koch Institut. Impfempfehlungen der Ständigen Impfkommission (STIKO) Stand März 1998. Epidemiologisches Bulletin. Robert Koch Institut, 15/98: 101 - 112

79 Deutsches Zentralkomitee zur Bekämpfung der Tuberkulose. Richtlinien zur medikamentösen Behandlung der Tuberkulose im Erwachsenen- und Kindesalter. Pneumologie 2001; 55: 494-511

80 Comstock GW, Caras GJ, Koplan JP. How much isoniazid is needed for prevention of tuberculosis among immunocompetent adults? Int J Tuberc Lung Dis 1999; 3: 847 - 850

81 Ormerod LP. Rifampicin ad isoniazide prophylactic chemotherapy for tuberculosis. Arch Dis Child 1998; 78: 169-171

82 Ena J, Valls V. Shourt course therapy with rifampicin plus isonoazid, compared with standard therapy with isoniazid for latent tuberculosis infection: a meta-analysis. Clin Infect Dis 2005; 40: 670-676

83 Rennie TW, Bothamley GH, Engova $D$ et al. Patient choice promotes adherence in preventive treatment for latent tuberculosis. Eur Respir J 2007; 30: 728 - 735

84 Spyridis NP, Spyridis PG, Gelesme A et al. The effectiveness of a 9-month regimen of isoniazid alone versus 3- and 4-month regimens of isoniazid plus rifampin for treatment of latent tuberculosis infection in children: results of an 11-year randomized study. Clin Infect Dis 2007; 45: 715-722

85 Thee S, Detjen AK, Quarcoo D et al. Ethambutol in paediatric tuberculosis: aspects of ethambutol serum concentration, efficacy and toxicity in children. Int J Tuberc Lung Dis 2007; 11: 965 - 971

86 Thee S, Detjen AK, Wahn U et al. Pyrazinamide serum levels in childhood tuberculosis. Int J Tuberc Lung Dis 2008; 12: 1099-1101

87 American Thoracic Society/Centers for Disease Control and Prevention/ Infectious Disease society of America. Treatment of tuberculosis. Am J Resp Crit Care Med 2003; 167: 63-662 
88 Ellard GA, Humphries MJ, Allen BW. Cerebrospinal fluid drug concentrations and the treatment of tuberculous meningitis. Am Rev Respir Dis 1993; 148: 650-655

89 Donald PR, Seifart HI. Cerebrospinal fluid concentrations of ethionamide in children with tuberculous meningitis. J Pediatr 1989; 115: $483-486$

90 Prasad K, Volmink J, Menon GR. Steroids for treating tuberculous meningitis. The Cochrane Database of Systematic Reviews, 2000, Issue 3. Art. No.: CD002244. DOI: 10.1002/14651858.CD002244

91 Schoeman JF, Van Zyl LE, Laubscher JA et al. Effect of corticosteroids on intracranial pressure, computed tomographic findings, and clinical outcome in young children with tuberculous meningitis. Pediatrics 1997; 99: 226-231

92 Thwaites GE, Macmullen-Price J, Tran TH et al. Serial MRI to determine the effect of dexamethasone on the cerebral pathology of tuberculous meningitis: an observational study. Lancet Neurol 2007; 6: $230-236$

93 Dooley DP, Carpenter JL, Rademacher S. Adjunctive corticosteroid therapy for tuberculosis: a critical reappraisal of the literature. Clin Infect Dis 1997; 25: $872-887$

94 Jain AK, Dhammi IK. Tuberculosis of the spine: a review. Clin Orthop Relat Res 2007; 460: 39-49

95 Ferebee SH. Controlled chemoprophylaxis trials in tuberculosis: A general review. Bibl Tuberc 1970; 26: 28-106

96 Otto HS, Magdorf K. Aktueller Stand der antituberkulösen Chemotherapie im Kindesalter. Prax Pneumol 1981; 35: 588 - 595

97 Ravenscroft A, Schoeman JF, Donald PR. Tuberculous granulomas in childhood tuberculous meningitis: radiological features and course. J Trop Pediatr 2001; 47: 5-12
98 Schoeman JF, Fieggen G, Seller $N$ et al. Intractable intracranial tuberculous infection responsive to thalidomide: report of four cases. J Child Neurol 2006; 21: $301-308$

99 Sneag DB, Schaaf HS, Cotton MF et al. Failure of chemoprophylaxis with standard antituberculosis agents in child contacts of multidrug-resistant tuberculosis. Pediatr Infect Dis J 2007; 26: 1142 - 1146

100 Katiyar SK, Bihari S, Prakash S et al. A randomized controlled trial of high-dose isoniazid adjuvant therapy for multidrug-resistant tuberculosis. Int J Tuberc Lung Dis 2008; 12: 139-145

\section{Bisher erschienene Beiträge aus dieser Serie}

1 Murray J. Die historische Entwicklung der Tuberkulose seit Robert Kochs Entdeckung des Tuberkelbazillus 1882. Pneumologie 2007; 61: $764-771$

2 Ulrichs T. Immunologie der Tuberkulose und Entwicklungsstand neuer Impfstoffe. Pneumologie 2008; 62: 143 - 148

3 Kalsdorf B, Strassburg A, Greinert $U$ et al. Klinik und Diagnose der Tuberkulose. Pneumologie 2008; 62: 284-294

4 Rüsch-Gerdes S, Hillemann D. Moderne mykobakteriologische Labordiagnostik. Pneumologie 2008; 62: 533-540

5 Hauer B, Brodhun B, Altmann D et al. Epidemiologie der Tuberkulose in der Welt und in Deutschland. Pneumologie 2008; 62: 583-594

6 Nienhaus A. Tuberkulose im Gesundheitswesen. Pneumologie 2009; 63: $22-29$ 